\title{
Perilaku Imitasi Pekerja Non Tuli pada Pekerja Tuli (Studi Komunikasi Kelompok di Media KamiBijak)
}

\author{
Elvina Marcella Wijaya, Suzy Azeharie \\ elvinamarcella99@gmail.com, suzya@fikom.untar.ac.id \\ Fakultas Ilmu Komunikasi Universitas Tarumanagara
}

\begin{abstract}
Human will always communicate throughout their lives and one of the examples is in the work environment. In a work group, a good communication between the employees is essential to finish the work optimally. It could be difficult to achieve the desired output when the communication is between employees with hearing loss and employees without hearing loss. The goal of this research is to determine the imitation behavior that conducted by employees without hearing loss toward employees with hearing loss in KamiBijak media, and also the difficulties they experienced while imitating. Theories used in this research are group communication theory, nonverbal communication, and imitation. A qualitative approach and case study method are also used for this research. The data of this research are obtained from passive observation and interviews with five informants. The result shows that the imitation done by employees without hearing loss is copying behavior because of interest and matched-dependent behavior because of motivation. Forms of nonverbal communication that imitated by employees without hearing loss in terms of kinesics are sign gestures, facial expression, eye contact, and physical contact such as touching. Other than that, there are also vocal examples such as lips movement adjusting their speech speed, and proxemics in form of personal space in communication. The difficulties that employees without hearing loss are experiencing is that the sign language that is done by the employees with hearing loss are too fast and using only one hand.
\end{abstract}

Keywords: Employees with Hearing Loss, Employees without Hearing Loss, Group Communication, Imitation

\begin{abstract}
Abstrak
Manusia dalam melaksanakan kehidupannya tidak dapat terlepas dari komunikasi, salah satunya dalam hal bekerja. Dalam suatu kelompok kerja, dibutuhkan komunikasi yang baik antara pekerja agar dapat menyelesaikan pekerjaan bersama dengan maksimal. Hal ini menjadi sulit jika komunikasi yang dilakukan melibatkan pekerja tuli dan pekerja non tuli. Penelitian ini bertujuan untuk mengetahui perilaku imitasi yang dilakukan pekerja non tuli pada pekerja tuli dalam kelompok kerja di media "KamiBijak" serta hambatan yang dialami dalam melakukan imitasi. Teori yang digunakan dalam penelitian ini adalah teori komunikasi kelompok, komunikasi nonverbal, dan imitasi. Penulis menggunakan pendekatan penelitian kualitatif dan metode studi kasus. Data hasil penelitian diperoleh melalui observasi pasif dan wawancara mendalam dengan lima informan. Hasil penelitian menunjukkan bahwa bentuk imitasi yang dilakukan pekerja non tuli adalah copying behavior karena ketertarikan dan matched-dependent behavior karena adanya motivasi. Bentuk komunikasi nonverbal yang diimitasi oleh pekerja non tuli meliputi kinesik yang terdiri dari gerakan isyarat, ekspresi wajah, kontak mata, serta sentuhan. Lalu, vokalik yaitu menggunakan gerak bibir dengan mengatur kecepatan berbicara, dan proksemik dalam bentuk penggunaan jarak pribadi dalam berkomunikasi. Hambatan yang dialami pekerja non tuli dalam melakukan imitasi adalah gerakan isyarat yang dilakukan pekerja tuli terlalu cepat dan hanya menggunakan satu tangan.
\end{abstract}


Elvina Marcella Wijaya, Suzy Azeharie: Perilaku Imitasi Pekerja Non Tuli pada Pekerja Tuli (Studi Komunikasi Kelompok di Media KamiBijak)

Kata Kunci: Imitasi, Komunikasi Kelompok, Pekerja Non Tuli, Pekerja Tuli

\section{Pendahuluan}

Manusia merupakan makhluk sosial yang tidak dapat hidup tanpa berdampingan dengan orang lain. Dalam melaksanakan kehidupannya, manusia tidak dapat terlepas dari komunikasi. Komunikasi merupakan proses sosial individuindividu dalam menggunakan simbol-simbol untuk menciptakan dan menginterpretasikan makna dalam suatu pesan (Mufida dan Azeharie, 2020).

Indera pendengaran manusia memiliki peran penting dalam berkomunikasi. Jika seseorang mengalami gangguan pada indera pendengarannya, maka akan berpengaruh terhadap komunikasi yang dilakukan karena orang tersebut tidak dapat mendengar pesan dari komunikator. Individu yang mengalami kehilangan atau kurang mampu dalam mendengar sehingga individu tersebut mengalami gangguan dalam melaksanakan kehidupan sehari-hari disebut tunarungu (Haenudin, 2013). Orang dewasa dengan gangguan pendengaran membutuhkan pekerjaan untuk dapat memenuhi kebutuhan hidupnya. Tetapi, sering kali orang dewasa dengan gangguan pendengaran dianggap tidak memiliki kemampuan bekerja oleh masyarakat.

Pada tanggal 19 September 2018 hadir media "KamiBijak" yang merupakan media ramah disabilitas pertama di Indonesia yang berlokasi di Gading Serpong, Tangerang Selatan. Media KamiBijak merupakan media daring berbasis video dengan bahasa visual dalam bentuk teks dan bahasa isyarat yang dapat memberikan kemudahan akses informasi untuk kelompok disabilitas. Selain membuat konten untuk disabilitas, KamiBijak juga membuka lapangan pekerjaan untuk kelompok disabilitas, terutama teman tuli. Selain pekerja tuli, media ini juga menerima pekerja non tuli untuk bergabung dan bekerja bersama di media KamiBijak (https://www.gatra.com/detail/news/425263/milenial/kamibijakmedia-jurnalistikdari-dan-untuk-teman-tuli diakses pada tanggal 24 September 2020 pukul 19.07 WIB).

Dalam kelompok kerja dibutuhkan komunikasi yang baik antar pekerja agar dapat mencapai tujuan bersama. Hal ini menjadi sulit ketika komunikasi yang terjadi dalam kelompok kerja melibatkan pekerja tuli dan pekerja non tuli. Pekerja tuli memiliki gangguan pendengaran sehingga komunikasi yang dilakukan tidak seperti komunikasi pada umumnya, melainkan lebih banyak melibatkan penggunaan komunikasi nonverbal. Agar dapat berkomunikasi dengan lancar dalam kelompok kerja, pekerja non tuli di media KamiBijak berusaha untuk meniru pekerja tuli dalam berkomunikasi. Hal tersebut dilakukan agar dapat diterima dalam lingkungan kerja serta dapat mencapai tujuan bersama. Perilaku imitasi yang dilakukan oleh pekerja non tuli bukan suatu hal yang mudah, dalam prosesnya memiliki banyak gangguan dan hambatan.

Penelitian ini bertujuan untuk mengetahui perilaku imitasi yang dilakukan pekerja non tuli pada pekerja tuli dalam kelompok kerja di media KamiBijak serta mengetahui hambatan-hambatan yang dialami oleh pekerja non tuli dalam melakukan imitasi tersebut. Alasan lainnya adalah karena penelitian ini belum pernah ada yang meneliti sebelumnya. 


\section{Metode Penelitian}

Penelitian ini menggunakan pendekatan kualitatif dan metode studi kasus. Penelitian kualitatif menurut Robert C. Bogdan dan Steven J. Taylor merupakan penelitian yang menghasilkan data deskriptif berupa kata-kata tertulis atau lisan dari orang-orang dan perilaku yang diamati (Moleong, 2015). Selain itu, studi kasus menurut John W. Creswell adalah suatu model yang menekankan pada eksplorasi dari suatu sistem yang terbatas pada satu atau beberapa kasus melalui pengumpulan data yang terperinci dan mendalam serta melibatkan berbagai sumber informasi yang kaya akan konteks (Yusuf, 2017). Penulis menggunakan metode penelitian studi kasus karena penelitian ini ingin menggali secara mendalam informasi mengenai suatu fenomena dalam kehidupan nyata yang penulis fokuskan pada kasus dalam kelompok kerja di media KamiBijak yang di dalamnya terdapat pekerja non tuli yang melakukan imitasi pada pekerja tuli agar dapat berinteraksi satu sama lain.

Dalam penelitian ini, penulis memilih pekerja non tuli di media KamiBijak sebagai subyek penelitian dan perilaku imitasi pekerja non tuli pada pekerja tuli di media KamiBijak sebagai obyek penelitian. Metode pengumpulan data yang digunakan dalam penelitian ini yaitu wawancara mendalam, observasi pasif, dan studi kepustakaan. Penulis melakukan wawancara mendalam dengan pekerja non tuli di media KamiBijak sesuai dengan kriteria yang telah ditentukan yaitu pekerja non tuli yang telah bergabung di media KamiBijak minimal dalam waktu tiga bulan dan melakukan imitasi pada pekerja tuli. Observasi pasif dilakukan dengan datang ke tempat kegiatan subyek penelitian yaitu kantor media KamiBijak yang berlokasi di Gading Serpong, Tangerang Selatan. Selama observasi, penulis hanya mengamati tindakan, perilaku, dan kegiatan yang dilakukan subyek penelitian tanpa ikut terlibat dalam kegiatan yang dilakukan oleh subyek yang diamati penulis. Selain itu, penulis menggunakan buku-buku dan jurnal penelitian yang berkaitan dengan Ilmu Komunikasi, yaitu komunikasi kelompok, komunikasi nonverbal, serta yang berkaitan dengan masalah dan metode penelitian sebagai sumber data yang relevan serta untuk memperkuat dan memperkaya penelitian penulis.

Teknik pengolahan dan analisis data yang digunakan dalam penelitian ini yaitu penulis melakukan observasi langsung dan wawancara dengan narasumber sebagai langkah awal, kemudian hasil observasi dan wawancara tersebut akan dipilih berdasarkan jawaban yang berkaitan dengan penelitian penulis. Setelah dipilih, akan diolah dan dianalisis untuk mengambil suatu kesimpulan. Dalam menguji keabsahan data, penulis menggunakan tiga teknik triangulasi yaitu triangulasi sumber dengan membandingkan informasi yang diperoleh dari berbagai sumber, triangulasi metode dengan membandingkan informasi yang diperoleh dari sumber yang sama dengan dua metode yang berbeda yaitu melalui observasi dan wawancara, serta triangulasi waktu dengan melakukan observasi dalam dua waktu yang berbeda, yaitu pagi hingga siang hari dan siang hingga sore hari.

\section{Hasil Temuan dan Diskusi}

Hasil observasi dan wawancara dengan narasumber menunjukkan bahwa komunikasi kelompok di media KamiBijak menggunakan komunikasi nonverbal berupa bahasa isyarat dan gerak bibir. Bahasa isyarat yang digunakan dalam kelompok kerja di media KamiBijak adalah Bahasa Isyarat Indonesia (Bisindo) karena merupakan bahasa isyarat alamiah dari lingkungan teman tuli, sehingga 
pekerja tuli lebih memahami Bahasa Isyarat Indonesia (Bisindo) dibandingkan dengan Sistem Bahasa Isyarat Indonesia (SIBI).

Gambar 1. Kelompok Kerja Media KamiBijak

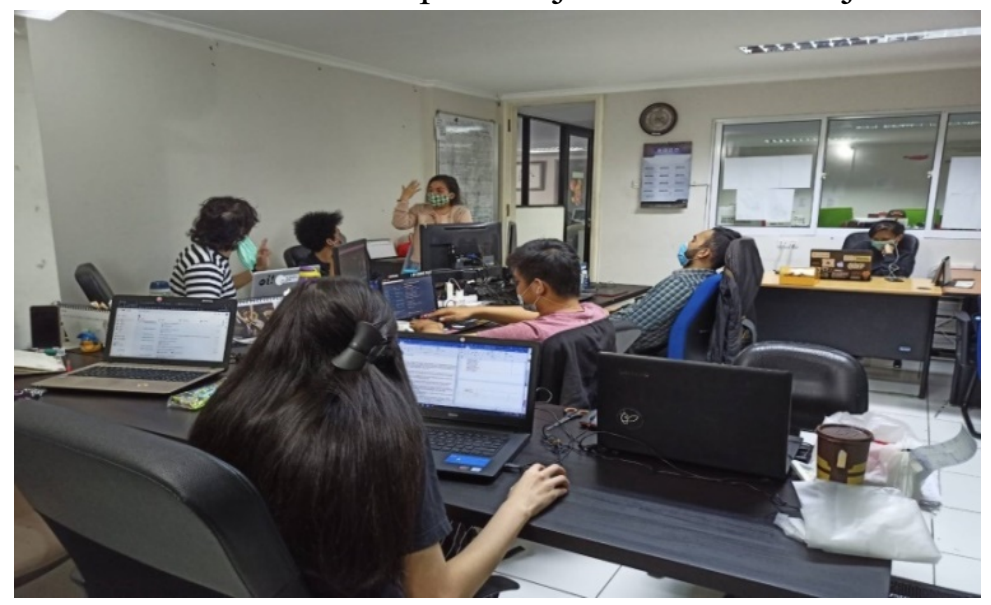

Sumber: Dokumentasi Pribadi pada 20 Oktober 2020

Komunikasi yang dilakukan oleh pekerja non tuli untuk berkoordinasi dengan pekerja tuli dalam kelompok kerja di media KamiBijak bukan suatu hal yang alamiah, melainkan melalui proses peniruan pada cara berkomunikasi pekerja tuli. Bagi pekerja non tuli di media KamiBijak, dalam melakukan imitasi pada cara berkomunikasi pekerja tuli bukan merupakan suatu hal yang mudah karena banyak sekali hambatan dalam prosesnya. Hambatan itu seperti ketika pekerja tuli saling berkomunikasi, gerakan isyarat yang dilakukan sangat cepat dan hanya menggunakan satu tangan. Hal tersebut membuat pekerja non tuli sulit untuk mengamati, memahami, dan meniru pekerja tuli.

Berdasarkan hasil observasi, penulis melihat bahwa pekerja non tuli sudah menggunakan berbagai bentuk komunikasi nonverbal yang menjadi komunikasi utama pekerja tuli di media KamiBijak. Bentuk-bentuk komunikasi nonverbal menurut Sugiarno dan Rahmanita Ginting terdiri dari kinesik yang merupakan gerakan atau bahasa tubuh yang meliputi gerakan isyarat, ekspresi wajah, kontak mata, dan sentuhan. Kedua, vokalik yang merupakan komunikasi nonverbal berupa suara tetapi tidak berupa kata-kata untuk menginterpretasikan simbol-simbol verbal, seperti bentuk vokal yang terdiri dari tinggi-rendahnya suara, keras atau lembutnya suara, kualitas suara yang meliputi penggunaan intonasi dalam berkomunikasi, serta kecepatan dalam berbicara. Terakhir, proksemik yang merupakan studi mengenai penggunaan jarak oleh manusia (Sugiarno dan Ginting, 2019).

Berbagai bentuk komunikasi nonverbal yang dilakukan oleh pekerja non tuli di media KamiBijak merupakan hasil imitasi pada cara berkomunikasi pekerja tuli. Bentuk-bentuk komunikasi nonverbal yang diimitasi oleh pekerja non tuli di media KamiBijak meliputi bentuk kinesik yang terdiri dari gerakan isyarat sebagai komunikasi utama di media KamiBijak didukung dengan penggunaan ekspresi wajah dan kontak mata, serta menggunakan sentuhan sebagai cara untuk memanggil. Tidak hanya dengan sentuhan, cara memanggil antar pekerja di media KamiBijak dapat menggunakan gerakan isyarat lainnya yaitu dengan melambaikan tangan ke arah yang dituju dan memanggil menggunakan nama isyarat, serta memanfaatkan saklar lampu dan sinar telepon genggam. Kemudian, terdapat bentuk vokalik yaitu 
menggunakan gerak bibir dengan mengatur kecepatan dalam berbicara. Terakhir, terdapat bentuk proksemik yaitu jarak antara pekerja tuli dan pekerja non tuli ketika berkomunikasi menggunakan jarak pribadi karena jarak tersebut tergolong dekat tetapi tidak intim.

Bukan merupakan waktu yang singkat bagi pekerja non tuli untuk dapat melakukan peniruan pada cara berkomunikasi pekerja tuli di media KamiBijak. Gabriel Tarde menjelaskan bahwa jika individu-individu yang berinteraksi dalam jangka waktu yang cukup panjang tetapi tidak menunjukkan peningkatan dalam peniruan merupakan suatu hal yang mustahil (Kartikasari dan Yenny, 2017).

Menurut Irene Nathania Setyanto, ia dapat berkomunikasi menggunakan bahasa isyarat di media KamiBijak melalui suatu proses peniruan pada cara berkomunikasi pekerja tuli. Proses untuk meniru tersebut dilakukan oleh Irene melalui pengamatan setiap harinya dan membiasakan diri untuk berkomunikasi dengan pekerja tuli. Irene tidak dapat menetapkan lamanya waktu untuk bisa berbahasa isyarat karena baginya hingga sekarang ini Irene masih berusaha untuk melakukan imitasi pada cara berkomunikasi pekerja tuli (wawancara dengan Irene Nathania Setyanto di kantor media KamiBijak, Tangerang Selatan pada tanggal 27 Oktober 2020 pukul 09.30 WIB).

Gambar 2. Irene Nathania S. Berkomunikasi dengan Pekerja Tuli

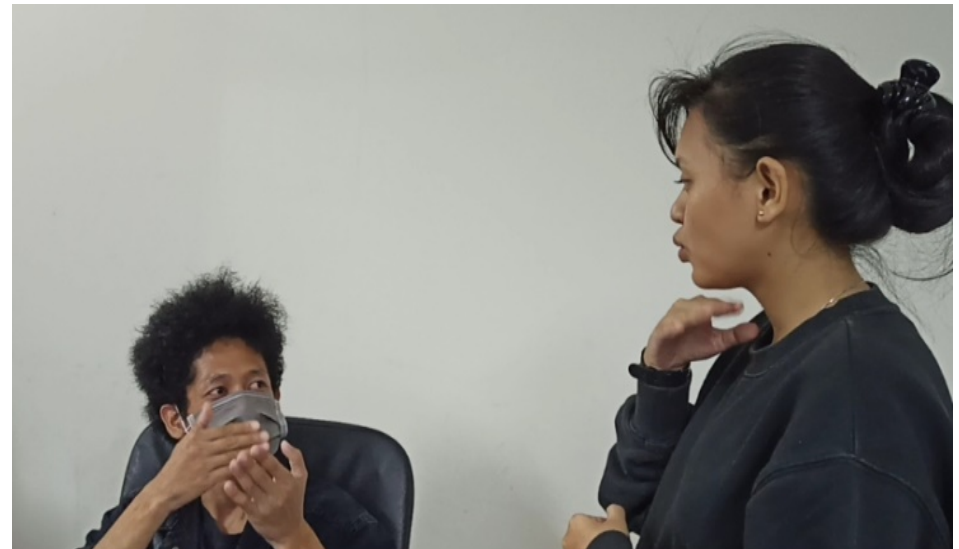

Sumber: Dokumentasi Pribadi pada 27 Oktober 2020

Sementara Fendrix Renaldo mengatakan bahwa sebelum ia bekerja di media KamiBijak, Fendrix magang terlebih dahulu selama tiga bulan. Selama magang, Fendrix membutuhkan waktu satu bulan untuk bisa menggunakan bahasa isyarat melalui proses peniruan pada pekerja tuli. Setelah magang selama tiga bulan, Fendrix melanjutkan perkuliahan sampai lulus lalu ia langsung melamar pekerjaan di media KamiBijak. Ketika masuk kerja di media KamiBijak, Fendrix mengalami kesulitan lagi dalam berkomunikasi dengan pekerja tuli. Jadi ia secara bertahap belajar lagi untuk memahami dan meniru komunikasi yang dilakukan pekerja tuli. Fendrix membutuhkan waktu sekitar dua minggu untuk bisa memahami dan meniru bahasa isyarat yang digunakan pekerja tuli di media KamiBijak (wawancara dengan Fendrix Renaldo di kantor media KamiBijak, Tangerang Selatan pada tanggal 27 Oktober 2020 pukul $11.00 \mathrm{WIB})$. 
Gambar 3. Fendrix Renaldo Berkomunikasi dengan Pekerja Tuli

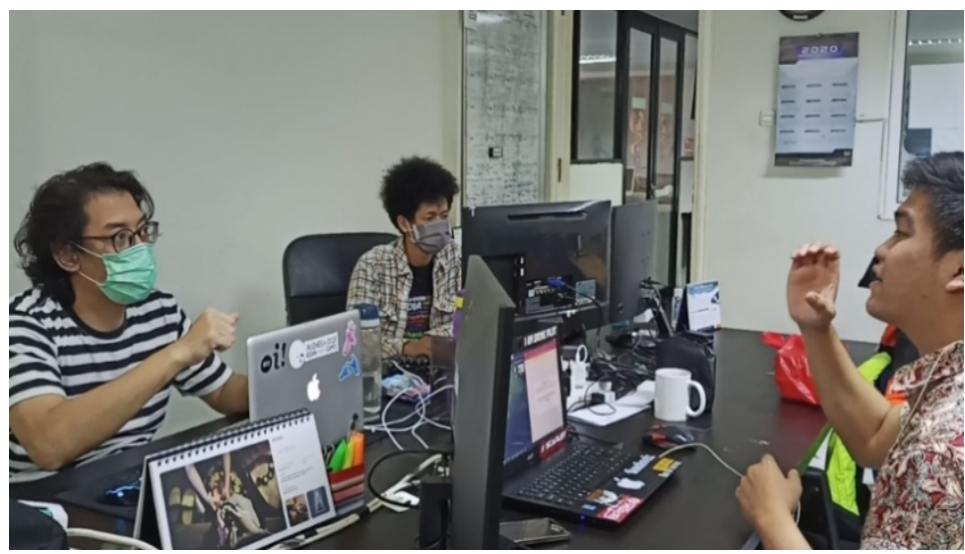

Sumber: Dokumentasi Pribadi pada 21 Oktober 2020

Kemudian menurut Lenny Astina, pada saat pertama kali bergabung di media KamiBijak sebagai pekerja magang, ia belum bisa berkomunikasi dengan pekerja tuli menggunakan bahasa isyarat. Tetapi seiring berjalannya waktu, Lenny terus memperhatikan dan mengamati pekerja tuli untuk secara perlahan meniru cara berkomunikasi pekerja tuli, terutama dalam menggunakan bahasa isyarat. Lenny membutuhkan waktu selama satu bulan untuk bisa berkomunikasi menggunakan bahasa isyarat seperti pekerja tuli. Namun, hingga sekarang ini ia masih terus belajar untuk menguasai serta meniru bahasa isyarat yang digunakan pekerja tuli (wawancara dengan Lenny Astina di kantor media KamiBijak, Tangerang Selatan pada tanggal 27 Oktober 2020 pukul $12.30 \mathrm{WIB}$ ).

Gambar 4. Lenny Astina Berkomunikasi dengan Pekerja Tuli

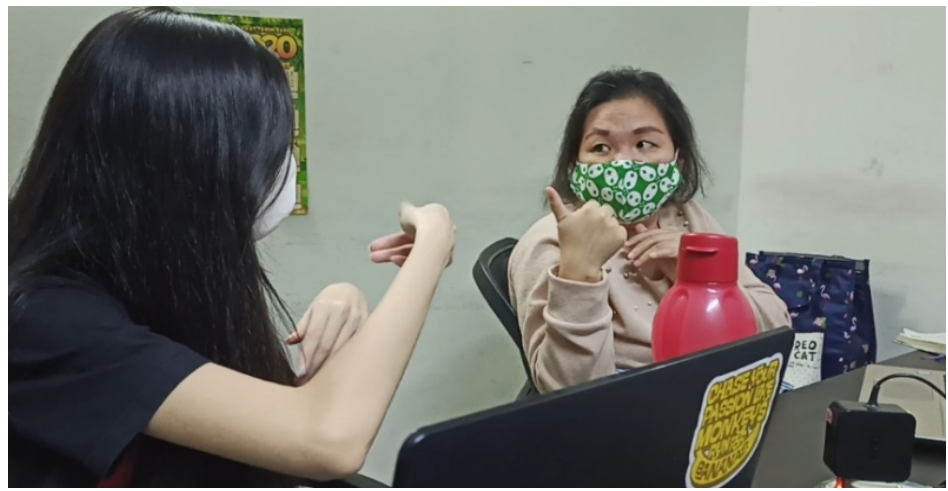

Sumber: Dokumentasi Pribadi pada 27 Oktober 2020

Julian B. Rotter menyatakan bahwa suatu perilaku imitasi akan terjadi bergantung pada harapan dari setiap individu (Susanto dan Heriyanto, 2013). Perilaku imitasi dapat dibedakan menjadi beberapa bentuk berdasarkan pada suatu alasan dalam melakukan imitasi. Bentuk-bentuk perilaku imitasi menurut Neale E. Miller dan John Dollard di antaranya seperti same behavior merupakan perilaku yang terjadi ketika dua atau lebih individu merespon situasi yang sama dengan cara yang sama, copying behavior merupakan perilaku yang terjadi ketika seseorang melakukan perilaku yang sesuai dengan perilaku orang lain yang didasarkan atas ketertarikan dan pengamatan yang jelas terhadap model yang ditiru, dan matched- 
dependent behavior merupakan perilaku seorang pengamat yang diperkuat untuk meniru tindakan dari seorang model. Perilaku jenis ini menjadi ciri dari perilaku orang dewasa yang berada dalam situasi yang asing (Hergenhahn dan Olson, 2010).

Bentuk perilaku imitasi yang dilakukan oleh pekerja non tuli pada pekerja tuli di media KamiBijak adalah copying behavior dan matched-dependent behavior. Bentuk copying behavior karena perilaku imitasi yang dilakukan oleh pekerja non tuli berdasarkan ketertarikan untuk meningkatkan kemampuan berbahasa. Sedangkan, bentuk matched-dependent behavior karena perilaku imitasi yang dilakukan oleh pekerja non tuli berdasarkan motivasi agar dapat berkomunikasi dan berkoordinasi dengan pekerja tuli dalam menyelesaikan pekerjaan bersama.

\section{Simpulan}

Komunikasi kelompok di media KamiBijak menggunakan bahasa isyarat dan gerak bibir. Bahasa isyarat yang digunakan yaitu Bahasa Isyarat Indonesia (Bisindo) karena merupakan bahasa isyarat alamiah dari lingkungan teman tuli. Selain itu, bentuk-bentuk komunikasi nonverbal yang digunakan oleh pekerja tuli dan pekerja non tuli di media KamiBijak meliputi bentuk kinesik, vokalik, dan proksemik. Pertama, kinesik terdiri dari gerakan isyarat, ekspresi wajah, kontak mata, serta sentuhan. Kedua, vokalik yaitu menggunakan gerak bibir dengan mengatur kecepatan berbicara. Ketiga, proksemik dalam bentuk penggunaan jarak pribadi dalam berkomunikasi.

Berbagai bentuk komunikasi yang dilakukan pekerja non tuli di media KamiBijak merupakan hasil imitasi pada cara berkomunikasi pekerja tuli. Bentuk perilaku imitasi yang dilakukan pekerja non tuli pada pekerja tuli di media KamiBijak yaitu copying behavior dan matched-dependent behavior. Bentuk copying behavior karena perilaku imitasi yang dilakukan berdasarkan ketertarikan. Sedangkan, bentuk matched-dependent behavior karena perilaku imitasi yang dilakukan berdasarkan motivasi agar dapat berkoordinasi dengan pekerja tuli dalam menyelesaikan pekerjaan bersama. Dalam melakukan imitasi, pekerja non tuli mengalami berbagai hambatan di antaranya seperti gerakan isyarat yang dilakukan pekerja tuli terlalu cepat dan hanya menggunakan satu tangan, sehingga membuat pekerja non tuli sulit untuk mengamati dan meniru pekerja tuli.

\section{Ucapan Terima Kasih}

Penulis mengucapkan terima kasih kepada seluruh pihak yang telah mendukung dan membantu penulis selama proses penelitian berlangsung sampai dengan terbitnya jurnal penelitian ini.

\section{Daftar Pustaka}

Ammurabi, Syah Deva. (2019). KamiBijak, Media Jurnalistik Dari dan Untuk Teman Tuli. <https://www.gatra.com/detail/news/425263/milenial/kamibijakmedia-jurnalistik-dari-dan-untuk-teman-tuli $>$ diakses pada tanggal 24 September 2020.

Haenudin. (2013). Pendidikan Anak Berkebutuhan Khusus Tunarungu. Jakarta: PT Luxima Metro Media. 
Hergenhahn, B.R. dan Matthew H. Olson. (2010). Theories of Learning (Teori Belajar). Jakarta: Kencana.

Kartikasari, Melyana Putri dan Yenny. (2017). Pengaruh Drama India di ANTV terhadap Perilaku Imitasi Ibu-Ibu Rumah Tangga di Kelurahan Kedung Baruk Surabaya. Jurnal Kajian Media, 1(2), 86-96.

Moleong, Lexy J. (2015). Metodologi Penelitian Kualitatif. Bandung: Remaja Rosdakarya.

Mufida, Yola Nahria dan Suzy S. Azeharie. (2020). Pengungkapan Diri Anak Tunarungu dalam Kelompok Teater Tujuh di Jakarta. Jurnal Koneksi, 4(1), 106-111.

Sugiarno dan Rahmanita Ginting. (2019). Komunikasi Nonverbal Guru dalam Meningkatkan Prestasi Belajar Siswa di SMP Muhammadiyah 7 Medan. Jurnal Komunikasi Persepsi, 2(1), 1-19.

Susanto, Eko Harry dan Anton Heriyanto. (2013). Fenomena Perilaku Imitasi Harlem Shake melalui New Media (Youtube) di Jakarta. Jurnal Inovasi, 7, 101-110.

Yusuf, Muri. (2017). Metode Penelitian: Kuantitatif, Kualitatif, dan Penelitian Gabungan. Jakarta: Kencana Prenada Media Group. 